\title{
Potassium channels in pulmonary arterial hypertension
}

\author{
Olivier Boucherat ${ }^{1}$, Sophie Chabot $^{1}$, Fabrice Antigny ${ }^{1,2}$, Frédéric Perros ${ }^{1,2}$, \\ Steeve Provencher ${ }^{1}$ and Sébastien Bonnet ${ }^{1}$ \\ Affiliations: \\ ${ }^{1}$ Pulmonary Hypertension Research Group, Centre de Recherche de l'Institut Universitaire de Cardiologie et \\ de Pneumologie de Québec, Université Laval, Québec, QC, Canada. \\ ${ }^{2}$ UMRS 999, INSERM and Univ. Paris-Sud, Laboratoire d'Excellence (LabEx) en Recherche sur le Médicament \\ et l'Innovation Thérapeutique (LERMIT), Centre Chirurgical Marie Lannelongue, Le Plessis Robinson, France.
}

\section{Correspondence:}

Olivier Boucherat, IUCPQ Research Centre, 2725, chemin Sainte-Foy M2670, Québec, QC, Canada, G1V 4 G5.

E-mail: olivier.boucherat@criucpq.ulaval.ca

ABSTRACT Pulmonary arterial hypertension $(\mathrm{PAH})$ is a devastating cardiopulmonary disorder with various origins. All forms of $\mathrm{PAH}$ share a common pulmonary arteriopathy characterised by vasoconstriction, remodelling of the pre-capillary pulmonary vessel wall, and in situ thrombosis. Although the pathogenesis of $\mathrm{PAH}$ is recognised as a complex and multifactorial process, there is growing evidence that potassium channels dysfunction in pulmonary artery smooth muscle cells is a hallmark of PAH. Besides regulating many physiological functions, reduced potassium channels expression and/or activity have significant effects on PAH establishment and progression. This review describes the molecular mechanisms and physiological consequences of potassium channel modulation. Special emphasis is placed on KCNA5 (Kv1.5) and KCNK3 (TASK1), which are considered to play a central role in determining pulmonary vascular tone and may represent attractive therapeutic targets in the treatment of PAH.

@ERSpublications

Comprehensive overview of the roles of potassium channels in the pathogenesis of pulmonary arterial hypertension http://ow.ly/QyBzX 


\section{Introduction}

Pulmonary hypertension (PH) encompasses a heterogeneous group of diseases, haemodynamically defined by a mean pulmonary artery pressure $>25 \mathrm{mmHg}$, that share histological similarities but differ in pathophysiology and prognosis. The current classification identifies five groups [1]. Among these, the pulmonary arterial hypertension (PAH) group includes idiopathic and hereditary entities, PAH associated with connective tissue disorders, congenital heart diseases or HIV infection as well as persistent $\mathrm{PH}$ of the newborn. PAH is characterised by proliferation and remodelling of the small pulmonary arteries, leading to increased pulmonary vascular resistance, subsequent right ventricular hypertrophy and ultimately death. It is currently accepted that endothelial cell dysfunction, originating from genetic defects, hypoxia, shear stress or inflammation, promotes the release of vasoconstrictors and mitogens that in turn trigger pulmonary artery smooth muscle cells (PASMCs) contraction, proliferation and resistance to apoptosis [2, 3]. Although pathogenesis of $\mathrm{PAH}$ is recognised as a complex and multifactorial process, numerous data has accumulated demonstrating the significant role of potassium $\left(\mathrm{K}^{+}\right)$channels in the cellular mechanisms underlying abnormal PASMC behaviour. In regulating potassium flow across the membrane and subsequent modulation of cytoplasmic free calcium concentration $\left(\left[\mathrm{Ca}^{2+}\right]_{\mathrm{cyt}}\right)$, potassium channels control a plethora of biological functions. This review summarises current knowledge regarding their involvement in the development of PAH.

\section{Overview of potassium channels}

Most of our knowledge regarding regulation of $\mathrm{K}^{+}$channel expression and function in $\mathrm{PAH}$ remains somewhat indirect and almost exclusively relies on the interpretation of electrophysiological data obtained by using pharmacological $\mathrm{K}^{+}$channel modulators. $\mathrm{K}^{+}$channels are transmembrane proteins connecting the cell interior to the extracellular environment by forming a pore in the cytoplasmic membrane. They are the largest family of membrane ion channels and are categorised into three major groups based on their structure as well as their electrophysiological and pharmacological properties: $2 \mathrm{TM}, 4 \mathrm{TM}$, and $6 \mathrm{TM}$, corresponding to the number of transmembrane (TM) spanning regions possessed by each of the $\alpha$-subunits that make up the channel. The first group consists of $\mathrm{K}^{+}$channels with two TM domains in each of their $\alpha$-subunits, also known as inward rectifier $\mathrm{K}^{+}\left(\mathrm{K}_{\mathrm{IR}}\right)$ channels. In contrast to the $2 \mathrm{TM}$ and 6TM families, 4TM channels possess two rather one pore-forming domain per subunit. 4TM channels are often referred as two-pore domain $\mathrm{K}^{+}$channels or $\mathrm{K}_{2 \mathrm{P}}$. Designated leak or background channels, they are mostly voltage-independent and contribute to setting the resting membrane potential. They respond to various physical and chemical stimuli such as mechanical stretch, $\mathrm{pH}$ and volatile anaesthetics. The $6 \mathrm{TM}$ channels are the largest class of $\mathrm{K}^{+}$channels and are subdivided into two types: calcium-activated $\mathrm{K}^{+}$ $\left(\mathrm{K}_{\mathrm{Ca}}\right)$ channels and voltage-dependent $\mathrm{K}^{+}\left(\mathrm{K}_{\mathrm{V}}\right)$ channels. $\mathrm{K}_{\mathrm{Ca}}$ channels are subdivided into $\mathrm{BK}$, IK, and SK channels according to conductance (big, intermediate, and small). Additional $\mathrm{K}^{+}$channel diversity is generated from alternative RNA splicing, post-translational modifications, the presence of both homomeric and heteromeric assemblies of the various $\alpha$-subunits, and the existence of accessory $\beta$-subunits modulating the functional properties of the channel. $\mathrm{K}^{+}$channels can be regulated at multiple levels by factors controlling channel expression, biosynthesis, trafficking by specialised chaperone proteins, insertion into the cell membrane, recycling, degradation, and activity. Alterations in these mechanisms can modify $\mathrm{K}^{+}$channel density and activity at the cell surface and therefore profoundly impact cell homeostasis.

\section{Potassium channels in regulation of cell proliferation and cell death}

Tonically active in vascular smooth muscle cells, $\mathrm{K}^{+}$channels are the major regulator of resting membrane potential. Under normoxic conditions, an outward $\mathrm{K}^{+}$current flows through these channels. This current maintains a resting membrane potential in the range of $-50--60 \mathrm{mV}$ and blocks calcium entry through voltage-activated $\mathrm{Ca}^{2+}$ channels. Inhibition of $\mathrm{K}^{+}$channel activity results in accumulation of positively charged $\mathrm{K}^{+}$ions within the cell. This renders the interior of the cell more positive resulting in membrane depolarisation and activation of voltage-activated $\mathrm{Ca}^{2+}$ channels, leading to an increase in $\left[\mathrm{Ca}^{2+}\right]_{\text {cyt }}$ and vasoconstriction (fig. 1). The rise in $\left[\mathrm{Ca}^{2+}\right]_{\text {cyt }}$ can be caused by two closely related mechanisms: 1) influx of $\mathrm{Ca}^{2+}$ from extracellular fluid, and 2) release of $\mathrm{Ca}^{2+}$ from intracellular storage sites such as the sarcoplasmic reticulum. Any prolonged variations in intracellular $\mathrm{K}^{+}$and $\mathrm{Ca}^{2+}$ concentrations directly influence cell survival and proliferation (fig. 1). By governing $\mathrm{K}^{+}$movement and intracellular osmolality that drives water flow across cell membrane, $\mathrm{K}^{+}$channels are crucial regulators for cell volume. In PASMCs, increased $\mathrm{K}^{+}$ efflux, either by transient transfection of a $\mathrm{K}_{\mathrm{V}}$ channel or by a $\mathrm{K}^{+}$channel activator, enhances cell death, a conserved mechanism characterised by cell shrinkage, chromatin condensation, nuclear fragmentation and apoptotic body formation [4-6]. Conversely, inhibition of $\mathrm{K}^{+}$efflux attenuates PASMC apoptosis [7]. The critical role of potassium channels in apoptosis has been substantiated in a study in which the anti-apoptotic protein Bcl-2 was overexpressed in rat PASMCs. Sustained expression of Bcl-2 caused a marked diminution of the $\mathrm{K}_{\mathrm{V}} 1.1, \mathrm{~K}_{\mathrm{V}} 1.5$ and $\mathrm{K}_{\mathrm{V}} 2.1$ transcript levels that subsequently decrease whole cell 
Healthy patient
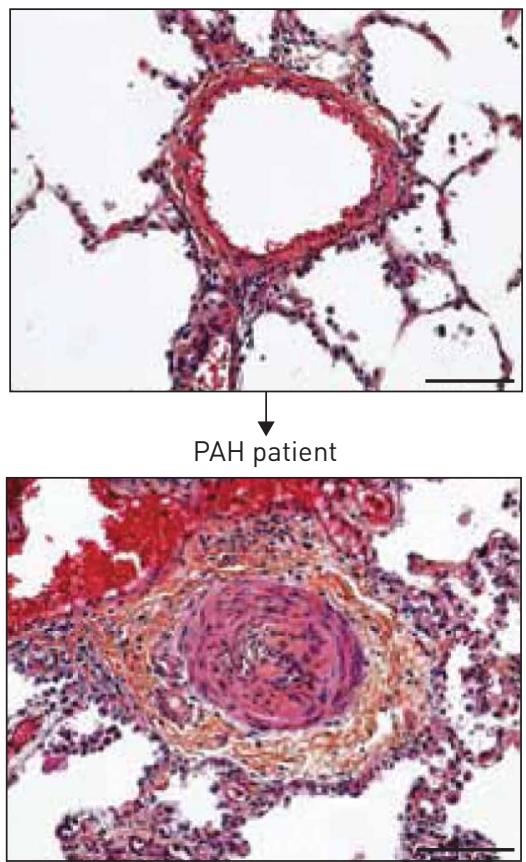

Hypoxia, mitogenic factors, inflammation

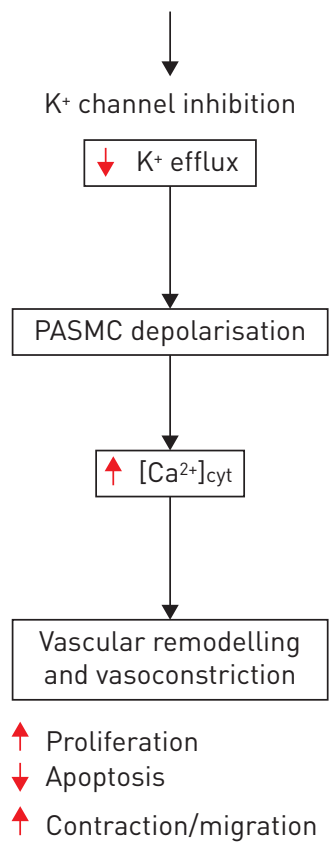

FIGURE $1 \mathrm{~K}+$ channel inhibition in pulmonary artery smooth muscle cells (PASMCs) leads to membrane depolarisation. This causes an increase in intracellular calcium levels that promotes cell proliferation and contraction as well as resistance to apoptosis and triggers pulmonary vasoconstriction and excessive vascular remodelling. Healthy patient scale bar $=100 \mu \mathrm{m}$; pulmonary arterial hypertension (PAH) patient scale bar $=100 \mu \mathrm{m} .\left[\mathrm{Ca}^{2+}\right]_{\text {cyt }}$ : cytoplasmic free calcium concentration.

$\mathrm{K}_{\mathrm{V}}$ current. Increases in $\mathrm{K}_{\mathrm{V}}$ current preceding PASMC apoptosis induced by staurosporine were suppressed by overexpression of Bcl-2, indicating that $\mathrm{K}_{\mathrm{V}}$ channel activation-mediated apoptotic volume decrease is an early prerequisite for apoptosis [8]. In addition, the consequences of high intracellular calcium levels on PASMC growth are well documented enforcing a cellular phenotype that is resistant to apoptosis and promoting cell proliferation [9]. Based on the physiological roles and properties of $\mathrm{K}^{+}$channels in PASMCs, the implication of $\mathrm{K}^{+}$channels in $\mathrm{PAH}$ has been the subject of intensive research.

\section{$\mathrm{K}_{\mathrm{V}}$ channel dysfunction as a contributing factor in the development of PAH}

$\mathrm{K}_{\mathrm{V}}$ channels are tetramers of $\alpha$-subunits, each comprised of six membrane-spanning domains (S1-S6) with a pore region and a voltage sensor. These tetramers are either homotetrameric (composed of a single type of $\alpha$-subunit) or heterotetrameric, which contributes to the unique biophysical properties of individual channels. Functional diversity of $\mathrm{K}_{\mathrm{V}}$ activities is further enhanced by association of accessory proteins with $\mathrm{K}_{\mathrm{V}}$ tetramers that can greatly impact channel ontogeny and function. The accessory $\beta$-subunits are members of the aldose reductase superfamily of NADPH oxidoreductases, providing a surface interaction with several proteins, including protein kinases and phosphatases. Like $\alpha$-subunits, each $\beta$-subunit has splice variants, contributing to tissue heterogeneity [10].

Activity of the 4-aminopyridine-sensitive $\mathrm{K}_{\mathrm{V}}$ channels in PASMCs play a pivotal role in regulating resting membrane potential, and $\left[\mathrm{Ca}^{2+}\right]_{\mathrm{cyt}}$, as well as in triggering hypoxia-mediated membrane depolarisation and pulmonary vasoconstriction [11-13]. Several members of the $\mathrm{K}_{\mathrm{V}}$ channel superfamily, including $\mathrm{K}_{\mathrm{V}} 1.2, \mathrm{~K}_{\mathrm{V}} 1.5, \mathrm{~K}_{\mathrm{V}} 2.1, \mathrm{~K}_{\mathrm{V}} 3.1$ and $\mathrm{K}_{\mathrm{V}}$ 9.3, have been found to be expressed by PASMCs [14-16]. Among these, particular attention has been given to $\mathrm{K}_{V} 1.5$ (encoded by the KCNA5 gene), preferentially expressed in the small resistance pulmonary arteries rather than in conduit pulmonary arteries and diminished in PASMC following hypoxia exposure $[14,15]$. Reduced expression of $\mathrm{K}_{\mathrm{V}} 1.5$ is a common denominator of human and experimental PAH suggesting an important role of this channel in the pathogenesis of various forms of $\mathrm{PH}$ [16-19]. Accordingly, in vivo gene transfer of $\mathrm{K}_{\mathrm{V}} 1.5$ was shown to reduce $\mathrm{PH}$ and to restore hypoxic pulmonary vasoconstriction in chronically hypoxic rats, adding further weight to its implication in PAH [20]. Although $\mathrm{K}_{\mathrm{V}} 1.5$ is considered as a potential therapeutic target, the molecular mechanisms leading to its reduced expression in this disease are not clear. Multiple mechanisms have been shown to contribute to its regulation (fig. 2). 


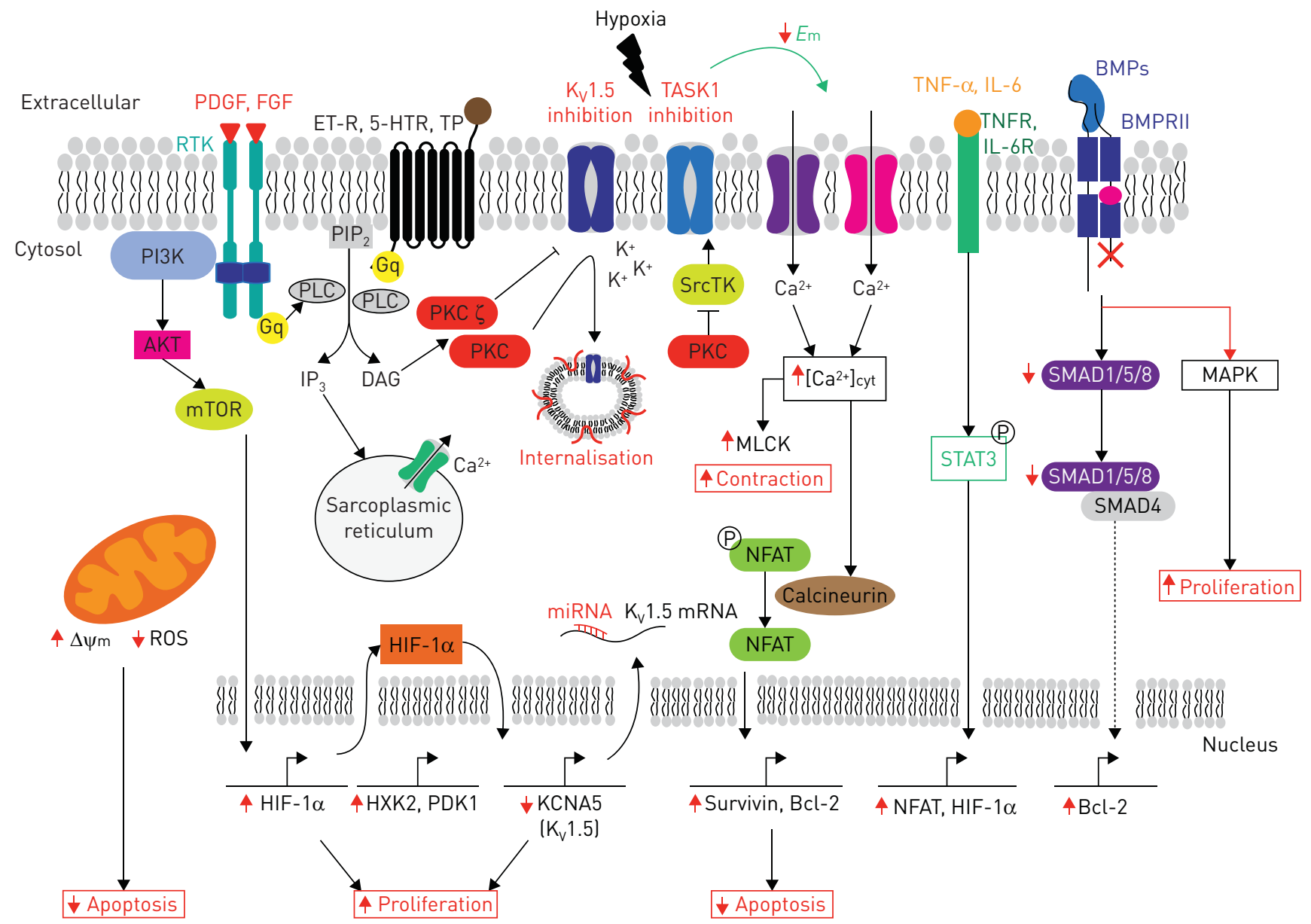

FIGURE 2 Proposed schematic representation of pathways involved in the regulation of $\mathrm{K}^{+}$current in pulmonary arterial hypertension pulmonary artery smooth muscle cells. $\left[\mathrm{Ca}^{2+}\right]_{\text {cyt: }}$ : cytoplasmic free calcium concentration; $E_{\mathrm{m}}$ : membrane potential; PI3K: phosphoinositide 3-kinase; PIP phosphatidylinositol-4,5-biphosphate; IP : inositol-1,4,5-triphosphate; DAG: diacylglycerol; PLC: phospholipase C; PKC: protein kinase C; SrcTK: Src family tyrosine kinase; MLCK: myosin light-chain kinase; ROS: reactive oxygen species; HIF-1 $\alpha$ : hypoxia-inducible factor-1 $\alpha$; PDK1: pyruvate dehydrogenase kinase, isozyme 1; HXK2: hexokinase 2; NFAT: nuclear factor of activated T-cells; STAT3: signal transducer and activator of transcription 3; SMAD: Mothers against decapentaplegic homologue; MAPK: mitogen-activated protein kinases; $\psi$ m: mitochondrial membrane potential; ET-R: endothelin receptor; BMP: bone morphogenetic protein; BMPRII: BMP receptor type II; TP: thromboxane receptor; 5-HTR: 5-hydroxytryptamine receptor; TNF- $\alpha$ : tumour necrosis factor- $\alpha$; IL-6: interleukin-6; PDGF: platelet-derived growth factor; FGF: fibroblast growth factor; TNFR: TNF receptor; IL-6R: IL-6 receptor; RTK: receptor tyrosine kinases.

\section{Activation of the phospholipase $C$-protein kinase $C$ cascade regulates $K_{V} 1.5$ channel function}

As mentioned earlier, pathogenesis of PAH is characterised by increased levels of pro-proliferative factors (serotonin, endothelin-1 and thromboxane A2 (TXA2)) and reduced levels of anti-proliferative factors, such as nitric oxide and prostacyclin, in the pulmonary vascular wall [2]. Decreased $\mathrm{K}_{\mathrm{V}} 1.5$-mediated current in PASMCs results from both direct effects of hypoxia and indirectly from hypoxia-induced expression of mitogenic factors.

The effects of serotonin (5-HT) on the pulmonary circulation have been of major interest since reports pinpointing the use of serotoninergic appetite suppressant drugs as a risk factor for the development of PAH [21]. The implication that serotonin is a key determinant of vessel remodelling was further confirmed by several observations highlighting: 1) high platelet and plasma levels of serotonin in patients with $\mathrm{PAH}[22], 2)$ prevention of $\mathrm{PAH}$ in animal models following inhibition of serotonin receptors $[23,24]$, and 3) a congenital predisposition to develop PAH in fawn-hooded rats caused by a defect in platelet serotonin storage [25]. Briefly, under pathological conditions, pulmonary endothelial cells produce high levels of serotonin that acts in a paracrine fashion on adjacent PASMCs to promote cell proliferation and contraction [26-28]. Results showing that exposure of human normotensive PASMCs to aminorex, fenfluramine or dexfenfluramide (appetite suppressant drugs that interact with the metabolism of serotonin) reduces the expression of $\mathrm{K}_{\mathrm{V}} 1.5$ and inhibits $\mathrm{K}^{+}$current support the notion that serotonin signalling causes $\mathrm{PAH}$, at least in part, through its effect on $\mathrm{K}_{\mathrm{V}}$ channel gene regulation [29, 30]. Cogolludo et al. [31] reported that serotonin treatment of PASMCs or Ltk ${ }^{-}$cells expressing cloned 
$\mathrm{hK}_{\mathrm{V}} 1.5$ markedly inhibited $\mathrm{K}_{\mathrm{V}}$ current and depolarised the cell membrane. Antagonists of 5-HT2A receptors abolished these effects. Under pathological circumstances, the binding of serotonin to the 5-HT2A receptors activates phospholipase C (PLC) through Gq family G-proteins that, in turn, lead to the cleavage of phosphatidylinositol-4,5-biphosphate $\left(\mathrm{PIP}_{2}\right)$ into inositol-1,4,5-triphosphate and diacylglycerol (DAG) (fig. 2) [32, 33]. The former triggers the release of $\mathrm{Ca}^{2+}$ from intracellular pools and the latter activates protein kinase $\mathrm{C}(\mathrm{PKC})$, which phosphorylates several intracellular substrates [33]. Likewise, inhibitors of PLC, conventional PKC and tyrosine kinase prevented the effects of serotonin on $\mathrm{K}_{\mathrm{V}}$ currents [31]. The authors found that $\mathrm{K}_{\mathrm{V}} 1.5$ coimmunoprecipitated with 5-HT2A receptors and caveolin-1 in native pulmonary arteries underscoring that this physical interaction could serve to cluster the 5-HT2A receptor and signalling proteins with the $\mathrm{K}^{+}$channel, allowing for specific modulation [31]. More importantly, Cogolludo et al. [31], demonstrated that stimulation with serotonin leads to caveolin-dependent internalisation of $\mathrm{K}_{\mathrm{V}} 1.5$, ensuring dynamic cell surface channel expression [31, 34]. Likewise, endocytosis of $\mathrm{K}_{\mathrm{V}} 2.1$ and $\mathrm{K}_{\mathrm{V}} 1.5$ channels has been reported to be a key mechanism in the control of $\mathrm{K}_{\mathrm{V}}$ channel activity, which is regulated by tyrosine phosphorylation mediated by Src kinase [35-37]. Thus, serotonin signalling appears to modulate $\mathrm{K}_{\mathrm{V}}$ current in PASMCs through direct alterations in $\mathrm{K}_{\mathrm{V}} 1.5$ trafficking and surface expression. This constitutes a mechanistic insight into how the levels of $\mathrm{K}_{\mathrm{V}} 1.5$ channels are downregulated in PAH (fig. 2).

$\mathrm{TXA}_{2}$ and prostacyclin are major arachidonic acid metabolites produced by vascular cells. $\mathrm{TXA}_{2}$ is a potent vasoconstrictor, whereas prostacyclin is a powerful vasodilator with antiplatelet and anti-proliferative effects. In both the primary and secondary forms of $\mathrm{PH}$, the balance between these two molecules is shifted toward $\mathrm{TXA}_{2}$ [38]. Interestingly, a TXA2 analogue (U46619), through activation of the thromboxane endoperoxide

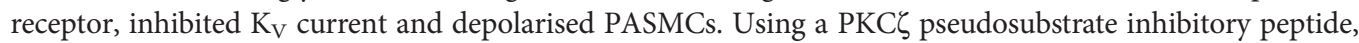
Cogolludo et al. [39] provided evidence for the role of this kinase as a link between thromboxane endoperoxide receptor activation and $\mathrm{K}_{\mathrm{V}}$ channel inhibition. The requirement for $\mathrm{PKC} \zeta$ in mediating TXA2-induced effects on $\mathrm{K}_{\mathrm{V}}$ current was further confirmed by the same group using $\mathrm{PKC} \zeta^{-1-}$ pulmonary arteries [40]. In addition, sequestosome1/p62, a stress-inducible protein regulated by the redox-sensitive transcription factor $\mathrm{Nrf2}$, was shown to serve as a scaffold protein acting as a physical link in the assembly of PKC $\zeta$-sequestosome1/p62-potassium channel complexes and to facilitate phosphorylation of $\mathrm{K}_{\mathrm{V}} \beta$ by $\mathrm{PKC} \zeta$, which induces inhibition of pulmonary arterial $\mathrm{K}_{\mathrm{V}} 1.5$ channels [41]. Consistent with this and similar to findings in $\mathrm{PKC}^{-1-}$ PASMCs, U46619 fails to inhibit $\mathrm{K}_{\mathrm{V}}$ currents in PASMCs deficient for sequestosome1/p62 [40]. Collectively, these data provide evidence for a modulatory role of sequestosome1/ p62 in the functional activity of $\mathrm{K}_{\mathrm{V}} 1.5$. It is worth noting that the subtypes of PKC involved in the regulation of PASMC $\mathrm{K}_{\mathrm{V}} 1.5$ channels vary among vasoconstrictors, since serotonin inhibits PASMC surface expression of $\mathrm{K}_{\mathrm{V}} 1.5$ channels in a $\mathrm{PKC} \zeta$-independent manner, contrary to inhibition byTXA2 [31].

The interaction between growth factor receptors and the $\mathrm{K}_{\mathrm{V}} 1.5$ channel was examined in Xenopus oocytes, an advantageous model for studying connections between receptors and ion channels. Coexpression of cloned mouse platelet-derived growth factor (PDGF) receptor and cloned $\mathrm{K}_{\mathrm{V}} 1.5$ in Xenopus oocytes, followed by PDGF stimulation led to a decline in the $K_{V} 1.5$ current amplitude. Taking advantage of the fact that the fibroblast growth factor (FGF) and PDGF receptors share structural similarity and are thought to have a similar mechanism of activation, the involvement of PLC $\gamma$ was explored using a mutated form of the FGF receptor that does not associate with PLC $\gamma$ [42]. In coexpression experiments, the mutant FGF receptor was not able to modulate $\mathrm{K}_{\mathrm{V}} 1.5$ current amplitude, providing strong evidence that increased PLC $\gamma$ activity is required for the reduction in $\mathrm{K}_{\mathrm{V}} 1.5$ current amplitude [42]. Considering the implication of FGF2 and PDGF in pulmonary vascular remodelling, the same mechanisms could conceivably occur in PAH PASMCs [43, 44].

\section{Bone morphogenetic protein signalling and potassium channels}

Several studies underscoring a critical role for bone morphogenetic protein (BMP) signalling in PAH have been published. A wide range of mutations, which are distributed throughout the coding region of the BMPR2 gene, have been identified in patients with PAH $[45,46]$. Consistently, transgenic mice expressing a dominant-negative Bmpr2 gene in smooth muscle cells (SM22-tet-BMPR2delx4+) develop increased pulmonary arterial pressure, associated with a modest increase in arterial muscularisation [47]. To test whether anomalies seen in SM22-tet-BMPR2delx4+ are mediated by reduced $\mathrm{K}_{\mathrm{V}}$ channel expression, YounG et al. [48] investigated the expression levels of several $\mathrm{K}_{\mathrm{V}}$ channels and revealed a pronounced diminution of $\mathrm{K}_{\mathrm{V}} 1.5$ protein expression in the lungs of transgenic mice. Consistent with this, treatment of PASMCs with recombinant BMP2 stimulates $\mathrm{K}_{\mathrm{V}} 1.5$ expression and was accompanied by increased current density in these cells; a functional effect blocked by an anti- $K_{V} 1.5$ antibody $[48,49]$. The mechanism of $\mathrm{K}_{\mathrm{V}} 1.5$ regulation by BMP signalling is unclear. Considering that BMP2 induces apoptosis in human PASMCs by reducing the expression of the anti-apoptotic protein $\mathrm{Bcl}-2$ and that overexpression of $\mathrm{Bcl}-2$ diminishes $\mathrm{K}_{\mathrm{V}} 1.5$ expression, it is, therefore, conceivable that the functional effects of signalling on $\mathrm{K}_{\mathrm{V}} 1.5$ can be attributed to alteration of Bcl-2 $[8,50]$. 
Transcriptional control: focus on hypoxia-inducible factor-1 $\alpha$ and nuclear factor of activated T-cells Although generation of reactive oxygen species (ROS) in mitochondria is known to be altered in $\mathrm{PH}$, the direction of these changes remains debated [51]. A cancer-like metabolic shift towards a glycolytic metabolism even in the presence of adequate oxygen, also designated the Warburg effect, has been demonstrated as a pathogenic element that can contribute to the development of PAH [52]. Mitochondrial dysfunction, characterised by hyperpolarisation of mitochondrial membrane potential and fragmentation, generates a low ROS environment causing a pseudo-hypoxic state that rapidly stabilises and triggers nuclear translocation of the master transcription regulator of the adaptive response to hypoxia, hypoxia-inducible factor (HIF)-1 $\alpha[18,53]$. The relationship between HIF- $1 \alpha$ activation and $\mathrm{K}_{\mathrm{V}} 1.5$ expression was investigated in $\mathrm{PAH}$ patients and in fawn-hooded rats, which develop spontaneous PAH with ageing [18]. Normoxic HIF-1 $\alpha$ activation (e.g. nuclear localisation) was almost universal in both cultured fawn-hooded rat PASMCs and human small pulmonary arteries from PAH patients. This correlates with a significant diminution of $\mathrm{K}_{\mathrm{V}} 1.5$ and $\mathrm{K}^{+}$current, membrane depolarisation and increased cytosolic calcium. Furthermore, expression of $\mathrm{K}_{\mathrm{V}} 1.5$ and $\mathrm{K}^{+}$current were restored in fawn-hooded rat PASMCs exposed to hyperoxia or transfected with an adenovirus coding for a dominant-negative form of HIF- $1 \alpha$, strengthening the fact that HIF- $1 \alpha$ activation accounts for the downregulation of $\mathrm{K}_{\mathrm{V}} 1.5$ [18].

A sustained increase in cytosolic $\mathrm{Ca}^{2+}$, due to potassium-dependent or independent mechanisms, is an important activator of the nuclear factor of activated T-cells (NFAT) family of transcription factors. In resting cells, NFAT proteins are phosphorylated and reside in the cytoplasm. Upon stimulation, NFAT are dephosphorylated by calcineurin, leading to its translocation into the nucleus where it can regulate gene expression [54] (fig. 2). Persistent activation of NFATc2 is a hallmark of human idiopathic PAH (IPAH) PASMCs [55]. Inhibition of its nuclear translocation by VIVIT or cyclosporine A was shown to reverse $\mathrm{K}_{\mathrm{V}} 1.5$ downregulation in normal PASMCs exposed to hypoxia. Moreover, in vivo NFAT inhibition by cyclosporine A treatment was shown to restore $\mathrm{K}_{\mathrm{V}} 1.5$ expression and reverse right ventricular and pulmonary artery medial hypertrophy in the monocrotaline (MCT)-induced rat model of PAH [55]. In agreement with the direct involvement of NFATc2 in $K_{V} 1.5$ regulation, serotonin treatment of PASMCs induced marked nuclear translocation of NFATc2 and a significant decrease in $\mathrm{K}_{\mathrm{V}} 1.5$ protein expression [19]. Although analyses of the KCNA5 gene revealed multiple putative NFAT binding elements in the $5^{\prime}$ untranslated region, there is no evidence of direct transcriptional regulation.

Several other elements also contribute to transcriptional control of KCNA5. Among these, c-jun, a member of the transcription factor activator protein-1 family was demonstrated to influence voltage-gated $\mathrm{K}^{+}$ channel activity in PASMCs. By infecting PASMCs with an adenovirus expressing c-Jun, Yu et al. [56] demonstrated that overexpression of this transcription factor was associated with a significant decrease in the amplitude of $\mathrm{K}_{\mathrm{V}}$ current by downregulating $\mathrm{K}_{\mathrm{V}} 1.5$ expression.

\section{Inflammation and potassium channels in PAH: an under studied field}

Pulmonary vascular inflammation (chemokine-driven leukocyte accumulation in the pulmonary vascular lesions of $\mathrm{PAH}$ ) and systemic inflammation (rise in blood levels of pro-inflammatory cytokines/ chemokines, C-reactive protein and auto-antibodies) are a common feature of human and experimental $\mathrm{PAH}[57,58]$. Although inflammation is recognised to play a significant role in the pathogenesis of PAH, relative few studies have investigated the functional effects of pro-inflammatory cytokines on $\mathrm{K}^{+}$current in PASMCs. SUTENDRA et al. [59] demonstrated that normal human PASMCs exposed to tumour necrosis factor (TNF)- $\alpha$ adopt a PAH phenotype with decreased $\mathrm{K}^{+}$current. The molecular mechanisms mediating this effect remain unclear, but can be attributed to the activation of STAT3 (signal transducer and activator of transcription 3); a transcription factor accounting for the modulation of the expression of several proteins such as HIF-1 $\alpha$ and NFAT (fig. 2) [60]. Indeed, increased STAT3 activation has been described in normal PASMCs treated with TNF- $\alpha$ or interleukin-6, suggesting that the decrease in $\mathrm{K}^{+}$current elicited by these inflammatory factors is due, at least in part, to a STAT3-dependent pathway [61, 62].

Evidence for single nucleotide polymorphisms in the KCNA5 gene that underlie susceptibility to PAH The identification of sequence polymorphisms is a key to understanding human genetic differences and diseases. The possible impacts of single nucleotide polymorphisms in KCNA5 on channel expression and function in PAH have been investigated $[63,64]$. In taking advantage of large cohorts restricted to the European Caucasian population, a KCNA5 rs10744676 variant, located in the putative promoter of KCNA5, was found to be associated with systemic sclerosis (SSc). Interestingly, analysis within the SSc cohort revealed that a KCNA5 rs10744676 C allele was associated with protection from PAH [64]. It is suggested that this polymorphism within a CACCC box, normally recognised by transcription factors of the Sp/Krüppel-like factor family, could affect transcription factor binding and hence influence KCNA5 transcription and expression levels. The functional consequences of this polymorphism remain to be addressed. Nevertheless, combined deletion, site-directed mutagenesis, pharmacological and chromatin 
immunoprecipitation approaches have shown that the Kcna5 promoter was critically dependent on Sp1 regulation via CACCC box motifs in murine vascular smooth muscle cells, highlighting the functional importance of CACCC box motifs to drive KCNA5 gene expression [65].

\section{Participation of microRNAs in the regulation of $K_{v} 1.5$ in PASMCs}

MicroRNAs are a class of short non-coding RNAs that act as negative regulators of gene expression by inhibiting the translation of target mRNAs, by promoting their degradation [66]. It is becoming increasingly apparent that the aberrant expression of microRNAs is causally related to a variety of disease states and PAH is no exception. Indeed, multiple deregulated microRNAs (e.g. miR17-92 cluster, miR-21, miR-143/145, miR-204 and miR-424/503) have been implicated in PAH [67, 68]. MicroRNA expression profiling between IPAH-PASMCs and normal PASMCs and subsequent bioinformatics microRNA target gene prediction were recently performed to examine the potential role of microRNAs in the downregulated $\mathrm{K}_{\mathrm{V}}$ channel expression and whole-cell $\mathrm{K}_{\mathrm{V}}$ current, characteristic of IPAH-PASMCs. Among microRNAs found to be selectively upregulated in IPAH-PASMCs, miR-29b was selected based on the predicted miR-29b-K 1.5 mRNA relationships. Forced expression of miR-29b in normal PASMCs decreased Kv1.5 protein expression, whereas inhibition of miR-29b in IPAH-PASMCs, using antisense oligonucleotides, rescued Kv1.5 protein levels, demonstrating that $\mathrm{K}_{\mathrm{V}} 1.5$ is a direct target of miR-29b in IPAH-PASMCs. These findings highlight an additional level of complexity to the regulation of $\mathrm{K}_{\mathrm{V}} 1.5$ (fig. 2) [69].

\section{Post-translational modifications of $K_{V} 1.5$ : implications in PAH?}

Protein post-translational modification (PTM) is a highly dynamic and crucial mechanism in which the functional properties of a protein are altered by the covalent addition of a chemical group or protein to its amino-acid residues. Independently of $\mathrm{PAH}, \mathrm{K}_{\mathrm{V}} 1.5$ has been shown to undergo diverse, reversible or irreversible PTM, including phosphorylation, S-acylation, palmitoylation, sumoylation, ubiquitination and glycosylation, which impact on ion channel expression, channel trafficking to the membrane, stability and activity [35, 70-74]. In response to oxidative stress, a sulfenic acid modification has been reported on a cysteine residue present in the C-terminal domain of $\mathrm{K}_{\mathrm{V}} 1.5$ that triggers internalisation of $\mathrm{K}_{\mathrm{V}} 1.5$, decreases current density, and diverts the channel from the recycling endosome towards degradation [75]. Moreover, tyrosine phosphorylation of $\mathrm{K}_{\mathrm{V}} 1.5$ and redox-sensitive $\mathrm{K}_{\mathrm{V}} 1.5$ sumoylation were also reported leading to its inactivation $[35,73]$. Using Xenopus oocytes as a model to study ion channels in a controlled in vivo environment, it was demonstrated that expression of the ubiquitin ligase Nedd4-2 declined $\mathrm{K}_{\mathrm{V}} 1.5$ currents by ubiquitinating and thereby reducing $\mathrm{K}_{\mathrm{V}} 1.5$ plasma membrane expression [74]. Finally, transfection of a $\mathrm{K}_{\mathrm{V}} 1.5$ palmitoylation-deficient mutant into Chinese hamster ovary cells has been shown to enhance the expression of surface current through enhanced localisation of the channel to the plasma membrane, indicating that palmitoylation reduced $\mathrm{K}_{\mathrm{V}} 1.5$ biological function [71]. No information is available on the PTM status of $\mathrm{K}_{\mathrm{V}} 1.5$ channels in PAH. Taking into account that metabolic pathways provide substrates for PTM and that PAH is recognised as a disorder associated with significant metabolic dysfunction, it can be assumed that major alterations in PTM of $\mathrm{K}^{+}$channels occur in PAH $[76,77]$. Nonetheless, the likely importance of these regulatory mechanisms remains to be explored.

Together, these findings demonstrate that $\mathrm{K}_{\mathrm{V}} 1.5$ is carefully regulated throughout the lifecycle of the channel and that alterations of these regulatory mechanisms can have important functional repercussions on $\mathrm{K}_{\mathrm{V}} 1.5$-mediated currents and $\mathrm{PAH}$ progression.

\section{Two-pore domain potassium channels in PAH}

$\mathrm{K}_{2 \mathrm{P}}$ channels are subdivided into six families, based on their sequence similarities and functional resemblance: TWIK, TREK, TASK, TALK, THIK, and TRESK [78]. Because the $\mathrm{K}_{2 \mathrm{P}}$ channels are typically open at negative membrane potential, they have been strongly implicated in establishing the background $\mathrm{K}^{+}$conductance known to stabilise the negative resting membrane potential and counterbalance depolarisation [78]. KCNK3 (also called TASK1) encodes a $\mathrm{pH}$-sensitive $\mathrm{K}_{2 \mathrm{P}}$ channel, which has been shown to be expressed by PASMCs and to contribute significantly to the resting membrane potential [79]. Indeed, TASK1 knockdown in human PASMCs caused a depolarisation of the resting membrane potential [80]. In direct connection with PAH, TASK1 was documented as being inhibited in human PASMCs by endothelin-1 through an endothelin receptor type A-PLC-PIP 2 -DAG-PKC-dependent signalling cascade [81]. In addition, hypoxia was shown to reduce the phosphorylation level of TASK1 and to inhibit TASK1 current in reducing the active phosphorylated state of the Src family tyrosine kinase (SrcTK). Inhibition of SrcTK depolarises PASMCs and reduces $\mathrm{K}_{\mathrm{V}}$ and $\mathrm{K}_{\mathrm{Ca}}$ currents [82]. This finding supports the observation that dasatinib, a dual Src/Abl kinase inhibitor, can cause PAH [83]. Moreover, it is important to point out that the KCNK3 channel was fully inhibited by serotonin in neurons suggesting that this mechanism may operate in PASMCs [84]. In keeping with previous findings that decreased efflux of $\mathrm{K}^{+}$from the cell is associated with resistance to apoptosis, overexpression of KCNK3 in neurons induces cell death, while its inactivation 
protects against cell death [85]. In addition to KCNK3, KCNK6 (also designated TWIK2), another member of the $\mathrm{K}_{2 \mathrm{P}}$ family, has recently been shown to be involved in $\mathrm{PH}$. Kcnk6-deficient mice present with an increase in right ventricular systolic pressure, indicating the development of vascular remodelling with $\mathrm{PH}$ [86]. Collectively, these findings provide compelling evidence that KCNK3 and KCNK6 work in concert with other oxygen-sensitive $\mathrm{K}^{+}$channels to regulate pulmonary vascular tone.

\section{KCNK3 (TASK1) as a cause of PAH}

Familial cases of PAH have long been recognised and are usually due to mutations in members of the transforming growth factor (TGF) signalling cascade [45, 46, 87]. BMPR2 mutations account for $\sim 70 \%$ of familial PAH (HPAH) and 15\% of patients with IPAH. To a lesser extent, heritable and idiopathic PAH are also associated with mutations of genes related to TGF- $\beta$ signalling, such as activin receptor-like kinase 1 (ALK1), endoglin (ENG), and mothers against decapentaplegic 9 (SMAD9) [88]. To date, a significant proportion of familial cases of $\mathrm{PAH}$ have not been linked to a genetic cause. Recent advances in genome sequencing technologies have provided unprecedented opportunities to identify mutations. Whole exome sequencing has gained popularity and was recently and successfully applied in a family in which multiple members presented PAH without identifiable mutations in any of the genes known to be linked to the disease. This approach allowed the discovery of $K C N K 3$ as a new predisposing gene for PAH [89]. In screening additional patients with IPAH and HPAH, a total of six KCNK3 variants were identified, all of which resulted in a loss of function of the channel at physiological $\mathrm{pH}$ that probably causes depolarisation of the resting membrane potential. The prevalence of KCNK3 mutations was $1.3 \%$ in IPAH and $3.2 \%$ in HPAH [89]. This study provides the first causal relationship between a $\mathrm{K}^{+}$channel and $\mathrm{PAH}$, and consequently $\mathrm{PAH}$ is now considered as a channelopathy. Surprisingly, neither right ventricular hypertrophy nor vessel remodelling were observed in $K c n k 3^{-/-}$mice underlying the fact that pulmonary arterial pressure of mutant mice was not elevated [90]. Divergence between human and rodent orthologous genes, existence of functional redundancy in rodents, and inter-species variability in expression levels may explain the apparent differences. In particular, KCNK3 does not form a functional channel in mouse PASMCs [91]. In mice, Kcnk3 function is probably replaced by other $\mathrm{K}^{+}$channels, for example Kcnk6. Accordingly, Kcnk6 mutant mice are more sensitive to hypoxia-induced $\mathrm{PH}$ [86]. Although involvement of KCNK3 is probable in human $\mathrm{PAH}$, analysis of its expression level in animal models mimicking the human disease is required. The generation of a Kcnk3 mutant rat, a popular model species in the field of $\mathrm{PH}$, will constitute a powerful tool to decipher its implication in vascular remodelling.

\section{Potassium channels: therapeutic opportunities}

Until recently, the treatment of PAH has focused on drugs that target vasoconstriction pathways. Since current vasodilator therapies are limited, research is now focusing on strategies that could reverse structural remodelling in the pulmonary arterial wall. Based on advances made in the physiopathogenesis of PAH, the anti-remodelling impact of multiple pharmacological agents have been tested in experimental models, and restoration of pulmonary artery $\mathrm{K}^{+}$channel expression and $\mathrm{K}^{+}$current are the parameters most often explored as a readout of their beneficial effects. For instance, dichloroacetate (DCA), which enhances oxidative phosphorylation by inhibiting the mitochondrial pyruvate dehydrogenase kinase, has been shown to prevent and reverse PAH in the MCT rat model. DCA treatment almost completely reversed the downregulation of $\mathrm{K}_{\mathrm{V}} 1.5$ observed in isolated PASMCs from MCT rats, improving $\mathrm{K}^{+}$current [17]. Similar results were observed in the MCT model using cyclosporine-A (an inhibitor of calcineurin-NFATc binding), fluoxetine (a selective serotonin reuptake inhibitor), and Plumbagin (a STAT3 inhibitor) [55, 91, 92]. Moreover, treatment with a selective survivin inhibitor was recently reported to significantly reduce pulmonary arterial pressure and to increase $\mathrm{K}_{\mathrm{V}} 1.5$ transcript levels in rats exposed to chronic hypoxia [93]. Based on published data showing that, in both human and experimental animal models of $\mathrm{PAH}, \mathrm{K}_{\mathrm{V}} 1.5$ is mainly subjected to transcriptional and intracellular protein trafficking regulations leading to reduced surface membrane expression, the clinical benefit of selective $\mathrm{Kv}$ channel openers appears questionable. As development of $\mathrm{PAH}$ is a multifactorial process, the disease should be approached from different therapeutic angles. This provides a strong rationale for combination therapy.

\section{Conclusion}

Numerous factors involved in $\mathrm{PAH}$ pathogenesis have been shown to impact $\mathrm{K}^{+}$channels at multiple levels. Reduced $\mathrm{K}^{+}$channel activity in PASMCs promotes cell proliferation, resistance to apoptosis and vasoconstriction contributing to vascular remodelling. Although the precise mechanisms by which KCNK3 leads to PAH remain largely unknown, its importance in controlling vascular functions offers great promise for future research. Molecules promoting indirect KCNA5 and KCNK3 expression, or direct gene transfer may constitute valuable therapeutic strategies for the treatment of $\mathrm{PAH}$. 


\section{References}

1 Simonneau G, Gatzoulis MA, Adatia I, et al. Updated clinical classification of pulmonary hypertension. J Am Coll Cardiol 2013; 62: Suppl., D34-D41.

2 Humbert M, Morrell NW, Archer SL, et al. Cellular and molecular pathobiology of pulmonary arterial hypertension. J Am Coll Cardiol 2004; 43: Suppl., 13S-24S.

3 Hassoun PM, Mouthon L, Barberà JA, et al. Inflammation, growth factors, and pulmonary vascular remodeling. J Am Coll Cardiol 2009; 54: Suppl., S10-S19.

4 Krick S, Platoshyn O, Sweeney $\mathrm{M}$, et al. Activation of $\mathrm{K}^{+}$channels induces apoptosis in vascular smooth muscle cells. Am J Physiol Cell Physiol 2001; 280: C970-C979.

$5 \quad$ Krick S, Platoshyn O, Sweeney $\mathrm{M}$, et al. Nitric oxide induces apoptosis by activating $\mathrm{K}^{+}$channels in pulmonary vascular smooth muscle cells. Am J Physiol Heart Circ Physiol 2002; 282: H184-H193.

6 Brevnova EE, Platoshyn O, Zhang S, et al. Overexpression of human KCNA5 increases IK V and enhances apoptosis. Am J Physiol Cell Physiol 2004; 287: C715-C722.

7 Krick S, Platoshyn O, McDaniel SS, et al. Augmented $\mathrm{K}^{+}$currents and mitochondrial membrane depolarization in pulmonary artery myocyte apoptosis. Am J Physiol Lung Cell Mol Physiol 2001; 281: L887-L894.

8 Ekhterae $\mathrm{D}$, Platoshyn $\mathrm{O}$, Krick $\mathrm{S}$, et al. Bcl-2 decreases voltage-gated $\mathrm{K}^{+}$channel activity and enhances survival in vascular smooth muscle cells. Am J Physiol Cell Physiol 2001; 281: C157-C165.

9 Kuhr FK, Smith KA, Song MY, et al. New mechanisms of pulmonary arterial hypertension: role of $\mathrm{Ca}^{2+}$ signaling. Am J Physiol Heart Circ Physiol 2012; 302: H1546-H1562.

10 Post JM, Hume JR, Archer SL, et al. Direct role for potassium channel inhibition in hypoxic pulmonary vasoconstriction. Am J Physiol 1992; 262: C882-C890.

11 Yuan XJ. Voltage-gated $\mathrm{K}^{+}$currents regulate resting membrane potential and $\left[\mathrm{Ca}^{2+}\right] \mathrm{i}$ in pulmonary arterial myocytes. Circ Res 1995; 77: 370-378.

12 Pongs O, Schwarz JR. Ancillary subunits associated with voltage-dependent $\mathrm{K}^{+}$channels. Physiol Rev 2010; 90: 755-796.

13 Post JM, Gelband $\mathrm{CH}$, Hume JR. $\left[\mathrm{Ca}^{2+}\right]$ i inhibition of $\mathrm{K}^{+}$channels in canine pulmonary artery. Novel mechanism for hypoxia-induced membrane depolarization. Circ Res 1995; 77: 131-139.

14 Archer SL, $\mathrm{Wu}$ XC, Thébaud $\mathrm{B}$, et al. Preferential expression and function of voltage-gated, $\mathrm{O}_{2}$-sensitive $\mathrm{K}^{+}$ channels in resistance pulmonary arteries explains regional heterogeneity in hypoxic pulmonary vasoconstriction: ionic diversity in smooth muscle cells. Circ Res 2004; 95: 308-318.

15 Wang J, Juhaszova $\mathrm{M}$, Rubin LJ, et al. Hypoxia inhibits gene expression of voltage-gated $\mathrm{K}^{+}$channel alpha subunits in pulmonary artery smooth muscle cells. J Clin Invest 1997; 100: 2347-2353.

16 Yuan XJ, Wang J, Juhaszova $\mathrm{M}$, et al. Attenuated $\mathrm{K}^{+}$channel gene transcription in primary pulmonary hypertension. Lancet 1998; 351: 726-727.

17 McMurtry MS, Bonnet S, Wu X, et al. Dichloroacetate prevents and reverses pulmonary hypertension by inducing pulmonary artery smooth muscle cell apoptosis. Circ Res 2004; 95: 830-840.

18 Bonnet S, Michelakis ED, Porter CJ, et al. An abnormal mitochondrial-hypoxia inducible factor- $1 \alpha-K v$ channel pathway disrupts oxygen sensing and triggers pulmonary arterial hypertension in fawn hooded rats: similarities to human pulmonary arterial hypertension. Circulation 2006; 113: 2630-2641.

19 Guignabert C, Tu L, Izikki M, et al. Dichloroacetate treatment partially regresses established pulmonary hypertension in mice with SM22 $\alpha$-targeted overexpression of the serotonin transporter. FASEB J 2009; 23: 4135-4147.

20 Pozeg ZI, Michelakis ED, McMurtry MS, et al. In vivo gene transfer of the $\mathrm{O}_{2}$-sensitive potassium channel Kv1.5 reduces pulmonary hypertension and restores hypoxic pulmonary vasoconstriction in chronically hypoxic rats. Circulation 2003; 107: 2037-2044.

21 Abenhaim L, Moride Y, Brenot F, et al. Appetite-suppressant drugs and the risk of primary pulmonary hypertension. International Primary Pulmonary Hypertension Study Group. N Engl J Med 1996; 335: 609-616.

22 Hervé P, Launay JM, Scrobohaci ML, et al. Increased plasma serotonin in primary pulmonary hypertension. Am J Med 1995; 99: 249-254.

23 Marcos E, Adnot S, Pham MH, et al. Serotonin transporter inhibitors protect against hypoxic pulmonary hypertension. Am J Respir Crit Care Med 2003; 168: 487-493.

24 Guignabert C, Raffestin B, Benferhat $\mathrm{R}$, et al. Serotonin transporter inhibition prevents and reverses monocrotaline-induced pulmonary hypertension in rats. Circulation 2005; 111: 2812-2819.

25 Sato K, Webb S, Tucker A, et al. Factors influencing the idiopathic development of pulmonary hypertension in the fawn hooded rat. Am Rev Respir Dis 1992; 145: 793-797.

26 Eddahibi S, Humbert M, Fadel E, et al. Serotonin transporter overexpression is responsible for pulmonary artery smooth muscle hyperplasia in primary pulmonary hypertension. J Clin Invest 2001; 108: 1141-1150.

27 Eddahibi S, Guignabert C, Barlier-Mur AM, et al. Cross talk between endothelial and smooth muscle cells in pulmonary hypertension: critical role for serotonin-induced smooth muscle hyperplasia. Circulation 2006; 113: $1857-1864$.

28 Guignabert C, Izikki M, Tu LI, et al. Transgenic mice overexpressing the 5-hydroxytryptamine transporter gene in smooth muscle develop pulmonary hypertension. Circ Res 2006; 98: 1323-1330.

29 Wang J, Juhaszova M, Conte JV Jr, et al. Action of fenfluramine on voltage-gated $\mathrm{K}^{+}$channels in human pulmonary-artery smooth-muscle cells. Lancet 1998; 352: 290.

30 Weir EK, Reeve HL, Huang JM, et al. Anorexic agents aminorex, fenfluramine, and dexfenfluramine inhibit potassium current in rat pulmonary vascular smooth muscle and cause pulmonary vasoconstriction. Circulation 1996; 94: 2216-2220.

31 Cogolludo A, Moreno L, Lodi F, et al. Serotonin inhibits voltage-gated $\mathrm{K}^{+}$currents in pulmonary artery smooth muscle cells: role of 5-HT2A receptors, caveolin-1, and KV1.5 channel internalization. Circ Res 2006; 98: 931-938.

32 Masson J, Sagné C, Hamon M, et al. Neurotransmitter transporters in the central nervous system. Pharmacol Rev 1999; 51: 439-464.

33 Berridge MJ, Bootman MD, Roderick HL. Calcium signalling: dynamics, homeostasis and remodelling. Nat Rev Mol Cell Biol 2003; 4: 517-529.

34 Sverdlov M, Shajahan AN, Minshall RD. Tyrosine phosphorylation-dependence of caveolae-mediated endocytosis. J Cell Mol Med 2007; 11: 1239-1250. 
Zhang S, Fantozzi I, Tigno DD, et al. Bone morphogenetic proteins induce apoptosis in human pulmonary vascular smooth muscle cells. Am J Physiol Lung Cell Mol Physiol 2003; 285: L740-L754.

51 Waypa GB, Schumacker PT. Hypoxic pulmonary vasoconstriction: redox events in oxygen sensing. J Appl Physiol (1985) 2005; 98: 404-414.

52 Tuder RM, Davis LA, Graham BB. Targeting energetic metabolism: a new frontier in the pathogenesis and treatment of pulmonary hypertension. Am J Respir Crit Care Med 2012; 185: 260-266.

53 Archer SL, Gomberg-Maitland M, Maitland ML, et al. Mitochondrial metabolism, redox signaling, and fusion: a mitochondria-ROS-HIF- $1 \alpha$-Kv1.5 $\mathrm{O}_{2}$-sensing pathway at the intersection of pulmonary hypertension and cancer. Am J Physiol Heart Circ Physiol 2008; 294: H570-H578.

54 Shou J, Jing J, Xie J, et al. Nuclear factor of activated T cells in cancer development and treatment. Cancer Lett 2015; 361: 174-184.

55 Bonnet S, Rochefort G, Sutendra G, et al. The nuclear factor of activated T cells in pulmonary arterial hypertension can be therapeutically targeted. Proc Natl Acad Sci USA 2007; 104: 11418-11423.

56 Yu Y, Platoshyn O, Zhang J, et al. c-Jun decreases voltage-gated $\mathrm{K}^{+}$channel activity in pulmonary artery smooth muscle cells. Circulation 2001; 104: 1557-1563.

57 Hassoun PM. Inflammation in pulmonary arterial hypertension: is it time to quell the fire? Eur Respir J 2014; 43: 685-688.

58 Cohen-Kaminsky S, Hautefort A, Price L, et al. Inflammation in pulmonary hypertension: what we know and what we could logically and safely target first. Drug Discov Today 2014; 19: 1251-1256.

59 Sutendra G, Dromparis P, Bonnet S, et al. Pyruvate dehydrogenase inhibition by the inflammatory cytokine TNF $\alpha$ contributes to the pathogenesis of pulmonary arterial hypertension. J Mol Med (Berl) 2011; 89: 771-783.

60 Paulin R, Meloche J, Bonnet S. STAT3 signaling in pulmonary arterial hypertension. JAKSTAT 2012; 1: $223-233$.

61 Courboulin A, Tremblay VL, Barrier M, et al. Krüppel-like factor 5 contributes to pulmonary artery smooth muscle proliferation and resistance to apoptosis in human pulmonary arterial hypertension. Respir Res 2011; 12 : 128.

62 Paulin R, Courboulin A, Meloche J, et al. Signal transducers and activators of transcription-3/pim1 axis plays a critical role in the pathogenesis of human pulmonary arterial hypertension. Circulation 2011; 123: $1205-1215$.

63 Remillard CV, Tigno DD, Platoshyn O, et al. Function of Kv1.5 channels and genetic variations of KCNA5 in patients with idiopathic pulmonary arterial hypertension. Am J Physiol Cell Physiol 2007; 292: C1837-C1853.

64 Wipff J, Dieudé P, Guedj M, et al. Association of a KCNA5 gene polymorphism with systemic sclerosis-associated pulmonary arterial hypertension in the European Caucasian population. Arthritis Rheum 2010; 62: 3093-3100.

65 Fountain SJ, Cheong A, Li J, et al. $\mathrm{K}_{\mathrm{V}} 1.5$ potassium channel gene regulation by Sp1 transcription factor and oxidative stress. Am J Physiol Heart Circ Physiol 2007; 293: H2719-H2725.

66 Lin S, Gregory RI. MicroRNA biogenesis pathways in cancer. Nat Rev Cancer 2015; 15: 321-333.

67 White K, Loscalzo J, Chan SY. Holding our breath: the emerging and anticipated roles of microRNA in pulmonary hypertension. Pulm Circ 2012; 2: 278-290.

68 Meloche J, Pflieger A, Vaillancourt M, et al. miRNAs in PAH: biomarker, therapeutic target or both? Drug Discov Today 2014; 19: 1264-1269.

69 Ayon R, Pohl N, Yamamura A, et al. miRNA-29b directly downregulates K+ channel expression and function in IPAH-PASMC. FASEB J 2015; 29: Suppl., 662.16.

70 Zhang L, Foster K, Li Q, et al. S-acylation regulates Kv1.5 channel surface expression. Am J Physiol Cell Physiol 2007; 293: C152-C161.

71 Jindal HK, Folco EJ, Liu GX, et al. Posttranslational modification of voltage-dependent potassium channel Kv1.5: COOH-terminal palmitoylation modulates its biological properties. Am J Physiol Heart Circ Physiol 2008; 294: $\mathrm{H} 2012-\mathrm{H} 2021$. 
72 Schwetz TA, Norring SA, Bennett ES. N-glycans modulate $\mathrm{K}_{\mathrm{V}} 1.5$ gating but have no effect on $\mathrm{K}_{\mathrm{V}} 1.4$ gating. Biochim Biophys Acta 2010; 1798: 367-375.

73 Benson MD, Li QJ, Kieckhafer K, et al. SUMO modification regulates inactivation of the voltage-gated potassium channel Kv1.5. Proc Natl Acad Sci USA 2007; 104: 1805-1810.

74 Boehmer C, Laufer J, Jeyaraj S, et al. Modulation of the voltage-gated potassium channel Kv1.5 by the SGK1 protein kinase involves inhibition of channel ubiquitination. Cell Physiol Biochem 2008; 22: 591-600.

75 Svoboda LK, Reddie KG, Zhang L, et al. Redox-sensitive sulfenic acid modification regulates surface expression of the cardiovascular voltage-gated potassium channel Kv1.5. Circ Res 2012; 111: 842-853.

76 Metallo CM, Vander Heiden MG. Metabolism strikes back: metabolic flux regulates cell signaling. Genes Dev 2010; 24: 2717-2722.

77 Paulin R, Michelakis ED. The metabolic theory of pulmonary arterial hypertension. Circ Res 2014; 115: 148-164.

78 González C, Baez-Nieto D, Valencia I, et al. $\mathrm{K}^{+}$channels: function-structural overview. Compr Physiol 2012; 2: 2087-2149.

79 Gurney AM, Osipenko ON, MacMillan D, et al. Two-pore domain K channel, TASK-1, in pulmonary artery smooth muscle cells. Circ Res 2003; 93: 957-964.

80 Olschewski A, Li Y, Tang B, et al. Impact of TASK-1 in human pulmonary artery smooth muscle cells. Circ Res 2006; 98: 1072-1080.

81 Tang B, Li Y, Nagaraj C, et al. Endothelin-1 inhibits background two-pore domain channel TASK-1 in primary human pulmonary artery smooth muscle cells. Am J Respir Cell Mol Biol 2009; 41: 476-483.

82 Nagaraj C, Tang B, Bálint Z, et al. Src tyrosine kinase is crucial for potassium channel function in human pulmonary arteries. Eur Respir J 2013; 41: 85-95.

83 Montani D, Bergot E, Günther S, et al. Pulmonary arterial hypertension in patients treated by dasatinib. Circulation 2012; 125: 2128-2137.

84 Talley EM, Lei Q, Sirois JE, et al. TASK-1, a two-pore domain $\mathrm{K}^{+}$channel, is modulated by multiple neurotransmitters in motoneurons. Neuron 2000; 25: 399-410.

85 Lauritzen I, Zanzouri M, Honoré E, et al. $\mathrm{K}^{+}$-dependent cerebellar granule neuron apoptosis. Role of task leak $\mathrm{K}^{+}$ channels. J Biol Chem 2003; 278: 32068-32076.

86 Pandit LM, Lloyd EE, Reynolds JO, et al. TWIK-2 channel deficiency leads to pulmonary hypertension through a rho-kinase-mediated process. Hypertension 2014; 64: 1260-1265.

87 Dresdale DT, Michtom RJ, Schultz M. Recent studies in primary pulmonary hypertension, including pharmacodynamic observations on pulmonary vascular resistance. Bull NY Acad Med 1954; 30: 195-207.

88 Soubrier F, Chung WK, Machado R, et al. Genetics and genomics of pulmonary arterial hypertension. J Am Coll Cardiol 2013; 62: Suppl., D13-D21.

89 Ma L, Roman-Campos D, Austin ED, et al. A novel channelopathy in pulmonary arterial hypertension. $N$ Engl $J$ Med 2013; 369: 351-361.

90 Manoury B, Lamalle C, Oliveira $\mathrm{R}$, et al. Contractile and electrophysiological properties of pulmonary artery smooth muscle are not altered in TASK-1 knockout mice. J Physiol 2011; 589: 3231-3246.

91 Zhai FG, Zhang XH, Wang HL. Fluoxetine protects against monocrotaline-induced pulmonary arterial hypertension: potential roles of induction of apoptosis and upregulation of Kv1.5 channels in rats. Clin Exp Pharmacol Physiol 2009; 36: 850-856.

92 Courboulin A, Barrier M, Perreault T, et al. Plumbagin reverses proliferation and resistance to apoptosis in experimental PAH. Eur Respir J 2012; 40: 618-629.

93 Fan Z, Liu B, Zhang S, et al. YM155, a selective survivin inhibitor, reverses chronic hypoxic pulmonary hypertension in rats via upregulating voltage-gated potassium channels. Clin Exp Hypertens 2015; 37: 381-387. 